\title{
Insulin Resistance Associated with Lower Rates of Weight Gain in Pima Indians
}

Boyd A. Swinburn, Bulangu L. Nyomba, Mohammed F. Saad, Francesco Zurlo, Itamar Raz, William C. Knowler, Stephen Lillioja, Clifton Bogardus, and Eric Ravussin

Clinical Diabetes and Nutrition Section and the Diabetes and Arthritis and Epidemiology Section, Phoenix Epidemiology and Clinical Research Branch, National Institute of Diabetes and Digestive and Kidney Diseases, National Institutes of Health, Phoenix, Arizona 85016

\section{Abstract}

Insulin resistance is commonly associated with obesity and noninsulin-dependent diabetes. Whereas it predicts the development of diabetes, its effect on body weight change is unknown. We measured glucose disposal rates at submaximally- and maximally-stimulating insulin concentrations in 192 nondiabetic Pima Indians and followed their weight change over $3.5 \pm 1.8$ y (mean $\pm S D)$.

Results: (a) Insulin-resistant subjects gained less weight than insulin-sensitive subjects (3.1 vs. $7.6 \mathrm{~kg}, P<0.0001$ ). (b) The percent weight change per year correlated with glucose disposal at submaximally- $(r=0.19, P<0.01)$ and maximallystimulating $(r=0.34, P<0.0001)$ insulin concentrations independent of sex, age, initial weight, and 24-h energy expenditure; the correlations were stronger for glucose oxidation than for glucose storage. (c) Weight gain was associated with an increase in insulin resistance more than four times that predicted from the cross-sectional data.

We conclude that insulin resistance is associated with a reduced risk of weight gain in nondiabetic Pima Indians. ( $J$. Clin. Invest. 1991. 88:168-173.) Key words: obesity • insulin resistance $\bullet$ glucose oxidation $\bullet$ weight gain $\bullet$ noninsulin-dependent diabetes mellitus

\section{Introduction}

Decreased insulin-mediated glucose disposal (insulin resistance) is found in virtually all patients with noninsulin-dependent diabetes mellitus (NIDDM) $)^{1}(1,2)$, and is a significant predictor of the disease in Pima Indians (3). Insulin resistance is also commonly associated with obesity, and probably represents the mechanism by which obesity exerts its influence on the development of NIDDM. However, the relationship, if any, of insulin resistance to change in weight is not known.

The Pima Indians of Arizona are very prone to NIDDM and obesity (4) and are insulin-resistant compared to Caucasians of the same body mass index (5). It is possible that insulin resistance could accelerate body weight gain, thereby predisposing to obesity as well as NIDDM. Indeed, it has been

Address correspondence to Dr. Eric Ravussin, Clinical Diabetes and Nutrition Section, 4212 N. 16th St., Phoenix, AZ 85016. Reprints unavailable.

Received for publication 3 October 1990 and in revised form 18 January 1991.

1. Abbreviations used in this paper: EMBS, estimated metabolic body size; MaxM, maximally-stimulating insulin concentration, NIDDM, noninsulin-dependent diabetes mellitus; SubmaxM, submaximallystimulating insulin concentration.

The Journal of Clinical Investigation, Inc.

Volume 88, July 1991, 168-173 previously suggested that insulin resistance, or the consequent hyperinsulinemia, may cause obesity via inhibition of lipolysis (6), reduced thermic effect of food (7), or increased appetite (8). This would imply a positive feedback relationship, whereby insulin resistance induced by weight gain would tend to increase further weight gain.

On the other hand, there is evidence in Pima Indians that a low rate of glucose to lipid oxidation (low respiratory quotient) is associated with a reduced rate of weight gain (9). Because a low rate of glucose oxidation contributes to a low overall rate of glucose disposal (oxidation plus storage), insulin resistance may also be associated with a reduced rate of weight gain.

To further examine this issue, we measured the glucose disposal rates in 192 nondiabetic Pima Indians and followed their weight change over a mean period of $3.5 \mathrm{yr}$. We found that insulin-resistant subjects gained less weight than insulinsensitive subjects.

\section{Methods}

Subjects. The subjects were Pima Indians living in the Gila River Indian Community in Arizona. They were participating in a longitudinal study of the development of NIDDM and obesity which included annual admissions to a metabolic research ward. Subjects were in good health as assessed by medical history, physical examination, and routine tests. All subjects gave informed consent and the studies were approved by the ethics committees of the National Institutes of Health, the Indian Health Service, and the Tribal Council of the Gila River Indian Community. During each 8-16-d admission to the metabolic ward, subjects were fed a weight-maintenance diet ( $50 \%$ of calories as carbohydrate, $30 \%$ as fat, and $20 \%$ as protein). Body composition was estimated by underwater weighing $(10,11)$. Body fat distribution was assessed by the waist:thigh circumference ratio. A minimum of $2 \mathrm{~d}$ after admission, all subjects underwent a 75-g oral glucose tolerance test. If a diagnosis of diabetes was made according to National Diabetes Data Group criteria (12), data from that and subsequent admissions were excluded from the analysis for that subject. This was done to avoid any bias that weight loss from glycosuria or therapeutic diets may have on the results. 195 subjects had at least one follow-up admission 6 mo or more after the initial admission. Three subjects were deleted as outliers: one subject had an intentional weight loss of $12.5 \%$ in $1 \mathrm{yr}$, and two had very large weight gains ( 41 and $48 \mathrm{~kg}$ ), each of these values being $>4$ SD from the respective group mean. Therefore, 192 subjects who had a total of 673 follow-up admissions were used for the analyses. Weight change between the first and the last admission was used for all analyses except the survival analysis in which each admission was considered separately. Of the 192 subjects, 109 also had 24-h energy expenditure measured in a respiratory chamber during admission, and these results were adjusted for individual differences in fat-free mass, fat mass, age, and sex as previously described (13). Euglycemic clamp data from the last admission were available in 124 of the subjects.

Hyperinsulinemic, euglycemic clamp. After 8-15 d, a two-step hyperinsulinemic, euglycemic clamp was performed by a modification of the method of DeFronzo et al. (14) as previously described (15). Briefly, $3-{ }^{3} \mathrm{H}$-glucose was infused for $220 \mathrm{~min}$ and hepatic glucose production was estimated at 100-120 min and at 200-220 $\mathrm{min}$ (16). Insulin, at a 
low dose ( $40 \mathrm{mU} /[$ body surface area in square meters] per minute), was infused from $120-220 \mathrm{~min}$, then at a high dose $\left(400 \mathrm{mU} / \mathrm{m}^{2}\right.$ per $\left.\mathrm{min}\right)$ from 220-320 min while euglycemia was maintained with a variable infusion of $20 \%$ dextrose. During the last $\mathbf{4 0} \mathrm{min}$ of the low-dose and high-dose infusions, the mean $( \pm \mathrm{SD})$ insulin concentrations were $910 \pm 265 \mathrm{pM}$ (mean coefficient of variation [C.V.] $=5.7 \pm 5.6 \%$ ) and $14,420 \pm 3,760 \mathrm{pM}(\mathrm{C} . \mathrm{V} .=7.1 \pm 11.7 \%)$, respectively, and the mean glucose concentrations were $5.2 \pm 0.3 \mathrm{mM}(\mathrm{C} . \mathrm{V} .=2.3 \pm 1.0 \%)$ and $5.2 \pm 0.3$ $\mathrm{mM}$ (C.V. $=2.8 \pm 1.1 \%)$, respectively. Insulin-mediated glucose disposal at submaximally- (SubmaxM) and maximally-stimulating (MaxM) insulin concentrations were calculated from the 40-min periods as described $(14,15)$

To account for differences in metabolic size among subjects, glucose disposal rates were divided by estimated metabolic body size (EMBS; fat-free body mass $+17.7 \mathrm{~kg}$ ) as described elsewhere (17), and then adjusted for the steady-state plasma glucose concentration (18). Concurrent, continuous, indirect calorimetry was performed with a clear, plastic, ventilated hood system (15) to estimate the rates of lipid and glucose oxidation. Nonoxidative carbohydrate disposal (or glucose storage) was calculated as the difference between total glucose disposal and glucose oxidation. Plasma glucose concentrations were measured by the glucose oxidase method (analyzer; Beckman Instruments, Inc., Fullerton, CA). Plasma insulin concentrations were determined by the Herbert modification (19) of the radioimmunoassay of Yalow and Berson (20).

Statistical methods. Statistical analyses were performed with the procedures of the SAS Institute (Cary, NC). We examined the effect of insulin resistance on weight change by three different approaches: $(a)$ The residuals of the linear relationship between MaxM and initial body weight were calculated for each subject as the difference between the measured value and the value predicted on the basis of the population regression line. The mean weight change (in kilograms) was compared between those with positive residuals (i.e., a high MaxM for their weight) and those with negative residuals (i.e., a low MaxM for their weight). A nonparametric test (Wilcoxon rank sum) was used to test for differences between the groups because the distributions of some of the variables were not normal within each group. The correlation between the actual residual values and percent weight change per year was also examined. (b) The relationships between SubmaxM and MaxM and weight change were examined by simple correlations (Pearson productmoment) and by linear regression analysis to determine if the relationships were dependent upon age, sex, or total 24-h energy expenditure. Weight change was expressed as percent weight change per year to minimize the confounding effects of different initial weights and follow-up periods. (c) The effects of SubmaxM and MaxM on weight gain (independent of age, sex, and initial weight) were also assessed by survival analysis using Cox's proportional hazards model (21). This analysis determines the incidence of reaching a set "failure" point, in this case arbitrarily defined as 5,10 , or $15 \mathrm{~kg}$ of weight gain. Because all the variables used in these analyses satisfied the proportional hazards assumptions, as described by Harrel (21), the ratio of rates of "failing" could be derived between any two values of SubmaxM or MaxM. We used the 10th and 90th percentile values.

The correlations between SubmaxM and MaxM and weight change were also assessed under certain conditions to check for biases in the results. (a) The exclusion of subjects after the diagnosis of diabetes ( $n$ $=16$ ) may have introduced some selection bias against insulin-resistant, weight-gaining subjects. Reanalysis was performed with these subjects included (up to the admission associated with their greatest body weight). (b) Since subjects with impaired glucose tolerance (2-h glucose 7.8-11 mM) may have received advice to lose weight, reanalysis was performed only on subjects with normal glucose tolerance $(n=126)$. (c) The possibility of spurious correlations arising from repeated measurements in the same subject was examined by using the means of the first and last values for SubmaxM and MaxM $(n=124)$ in place of the initial values as suggested by Oldham (22). (d) To check that the correlation was not dependent on short-term fluctuations in body weight, the minimum follow-up period was increased from 6 mo to 2 yr $(n=144)$

\section{Results}

The physical and metabolic characteristics of the subjects are shown in Tables I and II. The subjects (104 males and $88 \mathrm{fe}-$ males) were on average overweight, although a wide range of percent body fat (8-51\%) was represented. Over a mean followup period of $3.5 \mathrm{yr}(0.6-6.9 \mathrm{yr}), 148$ subjects had a positive and 44 had a zero or negative weight change (mean weight change $5.4 \pm 7.8 \mathrm{~kg}$, mean $\pm \mathrm{SD}, P<0.0001)$.

Comparison of insulin-sensitive and insulin-resistant subjects. The relationship between glucose disposal at the highdose insulin infusion (MaxM) and initial body weight is shown in Fig. $1(r=-0.38, P<0.0001)$. We examined the subsequent weight change in those subjects above the regression line (i.e., insulin-sensitive for their body weight) and those below the regression line (i.e., insulin-resistant for their body weight) (Table III). The insulin-resistant subjects were older, had higher insulin concentrations before and during the oral glucose tolerance test, and had less than half the weight gain of the insulinsensitive subjects ( $3.1 \mathrm{vs.} 7.6 \mathrm{~kg}, P<0.0001$ ). During the study, three subjects (one male, two females) of the insulin-sensitive group and 13 subjects (four males, nine females) of the insulinresistant group developed NIDDM. There was a significant correlation between the residual values (deviation from the re-

Table I. Physical Characteristics and Follow-up Data on 192 Nondiabetic Pima Indians

\begin{tabular}{|c|c|c|c|}
\hline & $\begin{array}{c}\text { Male } \\
(n=104)\end{array}$ & $\begin{array}{c}\text { Female } \\
(n=88)\end{array}$ & $\begin{array}{c}\text { All } \\
(n=192)\end{array}$ \\
\hline \multicolumn{4}{|l|}{ Initial data } \\
\hline Age $(y r)$ & $25.5 \pm 0.5(18-39)$ & $25.0 \pm 0.6(18-41)$ & $25.2 \pm 0.4$ \\
\hline Weight $(k g)$ & $97.4 \pm 2.7(50-181)$ & $91.2 \pm 2.2(48-170)$ & $94.6 \pm 1.8$ \\
\hline Body fat (\%) & $29 \pm 1(8-48)^{*}$ & $40 \pm 1(25-51)$ & $34 \pm 1$ \\
\hline Body mass index $\left(\mathrm{kg} / \mathrm{m}^{2}\right)$ & $33 \pm 1(18-60)^{\ddagger}$ & $36 \pm 1(20-63)$ & $34 \pm 1$ \\
\hline \multicolumn{4}{|l|}{ Follow-up data } \\
\hline \multirow[t]{2}{*}{ Duration $(y r)$} & $3.7 \pm 0.2(0.6-6.9)$ & $3.2 \pm 0.2(0.7-6.7)$ & $3.5 \pm 0.1$ \\
\hline & $5.0 \pm 0.8(-14.8-$ & $5.8 \pm 0.8(-10.8-$ & \\
\hline Weight change $(k g)$ & 26.5) & $32.1)$ & $5.4 \pm 0.6$ \\
\hline$\%$ weight change/yr & $1.6 \pm 0.3(-8.3-14.3)$ & $2.4 \pm 0.3(-6.6-14.6)$ & $2.0 \pm 0.2$ \\
\hline
\end{tabular}

Values are means \pm SEM with ranges in parentheses. ${ }^{*} P<0.001$ males vs. females. ${ }^{\ddagger} P<0.05$ males vs. females. 
Table II. Insulin-mediated Glucose Disposal at Low (SubmaxM) and High (MaxM) Insulin Concentrations in 192 Nondiabetic Pima Indians

\begin{tabular}{llcc}
\hline & \multicolumn{1}{c}{$\begin{array}{c}\text { Male } \\
(n=104)\end{array}$} & $\begin{array}{c}\text { Female } \\
(n=88)\end{array}$ & $\begin{array}{c}\text { All } \\
(n=192)\end{array}$ \\
\hline $\begin{array}{l}\text { Basal hepatic glucose production } \\
\text { Low-dose insulin infusion }\end{array}$ & $2.4 \pm 0.1(1.6-3.1)^{*}$ & $2.6 \pm 0.1(1.8-3.7)$ & $2.4 \pm 0.01$ \\
$\quad\left(40 \mathrm{mU} / \mathrm{m}^{2} \cdot \mathrm{min}\right)$ & & & \\
Total $($ SubmaxM) & $3.0 \pm 0.1(1.4-6.5)^{\ddagger}$ & $2.6 \pm 0.1(1.6-4.2)$ & $2.8 \pm 0.1$ \\
Oxidation & $1.9 \pm 0.1(0.5-3.4)^{8}$ & $2.1 \pm 0.1(1.1-3.3)$ & $2.0 \pm 0.1$ \\
Storage & $1.1 \pm 0.1(-0.1-3.7)^{*}$ & $0.5 \pm 0.1(-0.7-2.1)$ & $0.8 \pm 0.1$ \\
High-dose insulin infusion & & & \\
$\quad\left(400 \mathrm{mU} / \mathrm{m}^{2} \cdot \min \right)$ & & & \\
Total (MaxM) & $9.0 \pm 0.2(4.2-14.1)$ & $8.7 \pm 0.2(5.0-12.9)$ & $3.9 \pm 0.1$ \\
Oxidation & $3.3 \pm 0.1(1.7-4.8)^{8}$ & $3.5 \pm 0.1(2.0-4.8)$ & $3.4 \pm 0.1$ \\
Storage & $5.7 \pm 0.2(1.8-8.8)^{\ddagger}$ & $5.2 \pm 0.2(1.7-9.2)$ & $5.5 \pm 0.1$ \\
\hline
\end{tabular}

Values are means \pm SEM ranges in parentheses. Glucose disposal rates in $\mathrm{mg} / \mathrm{kg}$ EMBS $\cdot \min . \mathrm{EMBS}=$ fat-free mass $+17.7 \mathrm{~kg}(17)$.

${ }^{*} P<0.0001 ;{ }^{\ddagger} P<0.01 ;{ }^{8} P=0.05$ for male vs. female comparisons.

gression line) and the percent weight change per year $(r=0.36$, $P<0.0001)$. The correlations were similar if the relationships were calculated for males only $(r=0.39, P<0.0001)$ or females only $(r=0.38, P<0.001)$.

Correlations between glucose disposal and weight change. The absolute weight change (kilograms) over the study period was significantly correlated with initial weight $(r=0.18, P$ $<0.05)$ and length of follow-up $(r=0.20, P<0.01)$. Therefore, to minimize the effects of varying durations of follow-up and different initial body weights, we expressed weight change as a percentage weight change per year (which was not correlated with initial weight) for the remainder of the correlation analyses. This rate of percent weight change was significantly correlated with SubmaxM (Table IV, $r=0.19, P<0.01$ ) and MaxM (Table IV and Fig. 2, $r=0.34, P<0.0001$ ). The change in weight was more closely related to glucose oxidation than to glucose storage (Table IV), despite the fact that total glucose disposal is more highly correlated with glucose storage ( $r$ $=0.83, P<0.0001$ for SubmaxM; $r=0.95, P<0.0001$ for MaxM) than with glucose oxidation $(r=0.59, P<0.0001$ for SubmaxM; $r=0.60, P<0.0001$ for MaxM).

The weight change also correlated with age $(r=-0.22, P$



Figure 1. Correlation between glucose disposal at maximum-stimulating insulin concentrations (MaxM) and initial body weight in 104 male $(\Delta)$ and 88 female $(\bullet)$ nondiabetic Pima Indians $(r=-0.38, P$ $<0.0001, \beta=-0.03 \mathrm{mg} / \mathrm{kgEMBS} \cdot \min$ per $\mathrm{kg}$ ). Subjects above the regression line $(n=95)$ gained (mean) $7.6 \mathrm{~kg}$ and those below the line $(n=97)$ gained $3.1 \mathrm{~kg}(P<0.0001)$ over $3.5 \mathrm{yr}$. EMBS $=$ fat-free mass $+17.7 \mathrm{~kg}(17) .24$ observations hidden.
$<0.01$ ), total area under the insulin curve during an oral glucose tolerance test $(r=-0.21, P<0.01)$, but was not correlated with the glucose area under the curve $(r=-0.11, \mathrm{NS})$, fasting insulin $(r=-0.11, \mathrm{NS})$, fasting glucose $(r=-0.05$, NS), or waist:thigh ratio $(r=-0.14, \mathrm{NS})$. When these variables were analyzed in multiple linear regression models with either SubmaxM or MaxM, the predictors of weight gain were higher SubmaxM $(P<0.05)$, younger age $(P<0.05)$, and female sex $(P<0.05)$ in one model $\left(r^{2}=0.09, P<0.001\right)$, and higher MaxM $(P<0.0001)$, younger age $(P=0.08)$, and female sex $(P$ $<0.05)$ in the other $\left(r^{2}=0.15, P<0.0001\right)$. The group was divided into "less obese" and "more obese" according to the mean initial weight for each sex. The effect of SubmaxM and MaxM on weight change was stronger in the less obese group ( $P$ $<0.05, P<0.0001)$ than in the more obese group $(P=\mathrm{NS}, P$ $<0.02)$. In the subgroup of 109 subjects in whom data from the respiratory chamber were available, the effect of SubmaxM $(P$ $<0.05)$ and $\operatorname{MaxM}(P<0.05)$ on the percent weight change per year was independent of age, sex, and the 24-h energy expenditure adjusted for fat-free mass, fat mass, age, and sex.

When the correlation analyses were checked for possible biases (see Methods for details), the relationships between SubmaxM and MaxM and the rate of weight change were maintained. (a) Inclusion of 16 subjects after the diagnosis of diabetes $(r=0.22, P<0.01 ; r=0.33, P<0.0001$, respectively, for SubmaxM and MaxM, $n=192$ ). (b) Only normal glucose tolerant subjects used ( $r=0.22, P<0.05 ; r=0.36, P<0.0001, n$ $=126)$. (c) Mean, rather than initial, values for SubmaxM and MaxM used $(r=0.18, P<0.05 ; r=0.23, P<0.05, n=124)$. (d) Follow-up periods of $<2$ yr excluded $(r=0.19, P<0.05 ; r$ $=0.38, P<0.0001, n=144$ ).

Survival analysis of weight gain. Survival analysis (using the proportional hazards model) examines the cumulative incidence of reaching a predefined "failure" point. We defined three "failure" points: $5 \mathrm{~kg}$, reached by 107 subjects; $10 \mathrm{~kg}$ reached by 58 subjects; and $15 \mathrm{~kg}$ reached by 30 subjects. MaxM was a significant predictor of weight change (independent of initial weight, age, and sex $)$ at $5 \mathrm{~kg}(P<0.01), 10 \mathrm{~kg}(P$ $<0.01)$, and $15 \mathrm{~kg}(P<0.01)$, whereas SubmaxM was signifcant at $10 \mathrm{~kg}(P<0.05)$, borderline at $15 \mathrm{~kg}(P=0.05)$, but not at $5 \mathrm{~kg}(P=0.12)$. The hazard rate ratios for "failure" at $10 \mathrm{~kg}$ between the 90 th percentile (SubmaxM $=4.1, \operatorname{MaxM}=11.5$ 
Table III. Initial and Follow-up Parameters of 192 Nondiabetic Pima Indians Divided into Insulin-sensitive and Insulin-resistant Groups

\begin{tabular}{lccc}
\hline & $\begin{array}{c}\text { Insulin-sensitive } \\
(56 \mathrm{M} / 39 \mathrm{~F})\end{array}$ & $\begin{array}{c}\text { Insulin-resistant } \\
(48 \mathrm{M} / 49 \mathrm{~F})\end{array}$ & $P$ value \\
\hline Initial parameters & & & \\
Age $(y r)$ & $23.9 \pm 0.5(18-37)$ & $26.7 \pm 0.6(18-41)$ & $<.001$ \\
Weight $(\mathrm{kg})$ & $93.4 \pm 2.5(48-166)$ & $95.8 \pm 2.5(50-181)$ & 0.52 \\
Body fat $(\%)$ & $33 \pm 1(8-51)$ & $34 \pm 1(12-50)$ & 0.32 \\
SubmaxM $(\mathrm{mg} / \mathrm{kgEMBS} \cdot \mathrm{min})^{*}$ & $3.2 \pm 0.1(1.6-6.5)$ & $2.3 \pm 0.1(1.4-4.8)$ & - \\
MaxM $(\mathrm{mg} / \mathrm{kgEMBS} \cdot \mathrm{min})^{*}$ & $10.3 \pm 0.1(7.4-14.1)$ & $7.3 \pm 0.1(4.2-9.0)$ & $<0.0001$ \\
Fasting insulin $(p M)$ & $220 \pm 10(65-446)$ & $324 \pm 17(79-863)$ & $<0.0001$ \\
OGTT insulin $(p M \cdot 3 \mathrm{~h})^{\ddagger}$ & $1021 \pm 63(198-3257)$ & $1797 \pm 104(489-5400)$ & $<0.01$ \\
Fasting glucose $(\mathrm{mM})$ & $5.1 \pm 0.1(4.2-5.9)$ & $5.3 \pm 0.1(4.2-6.9)$ & $<0.0001$ \\
OGTT glucose $(\mathrm{mM} \cdot 3 \mathrm{~h})^{\ddagger}$ & $6.5 \pm 0.1(4.6-9.0)$ & $7.5 \pm 0.1(4.7-10.7)$ & 0.73 \\
Follow-up parameters & $3.5 \pm 0.2(0.6-6.9)$ & $3.5 \pm 0.2(0.8-6.5)$ & $<0.0001$ \\
Follow-up duration $(y r)$ & $7.6 \pm 0.8(-9.8-32.1)$ & $3.1 \pm 0.7(-14.8-20.4)$ & \\
Weight change $(\mathrm{kg})$ & & & \\
\end{tabular}

Values are means \pm SEM with ranges in parentheses. * Glucose disposal rates. These values are different between groups by experimental design. Insulin concentrations (mean \pm SD) during clamp for insulin-sensitive and insulin-resistant groups: SubmaxM 856 $\pm 256,965 \pm 263 \mathrm{pM}(P$ $<0.01)$. MaxM $13990 \pm 3540,14840 \pm 3940 \mathrm{pM}(P=\mathrm{NS})$. EMBS $=$ fat-free mass $+17.7 \mathrm{~kg}(17){ }^{\ddagger}$ Mean concentration throughout oral glucose tolerance test.

$\mathrm{mg} / \mathrm{kgEMBS} \cdot \mathrm{min})$ and the tenth percentile $($ SubmaxM $=1.9$, $\operatorname{MaxM}=6.1 \mathrm{mg} / \mathrm{kgEMBS} \cdot \mathrm{min})$ were $3.8(95 \%$ confidence interval 1.7-8.6) for MaxM and 2.2 (95\% C.I. 1.0-4.9) for SubmaxM. The hazard rate ratio is the ratio of the hazards (rates of "failure" per person per time) in subjects at two levels of a predictor variable. It is approximately equal to the cumulative incidence (or risk) ratio at various periods of follow-up. Thus, the risk of a person with a low MaxM $(6.1 \mathrm{mg} / \mathrm{kgEMBS} \cdot \mathrm{min})$ gaining $10 \mathrm{~kg}$ is about one-quarter to one-third that of a person with a high MaxM (11.5 mg/kgEMBS - $\mathrm{min})$. This is shown in Fig. 3 with the middle group representing the overall group mean.

Table IV. Simple Correlations between Initial Parameters and Subsequent Weight Change in 192 Nondiabetic Pima Indians

\begin{tabular}{|c|c|c|}
\hline Independent variable & $r$ & $P$ \\
\hline Age $(y r)$ & -0.22 & $<0.01$ \\
\hline Initial weight $(\mathrm{kg})$ & -0.01 & NS \\
\hline Body fat (\%) & 0.03 & : NS \\
\hline Waist/thigh ratio & -0.14 & NS \\
\hline Fasting insulin $(p M)$ & -0.11 & NS \\
\hline Insulin area under OGTT curve ( $p M)$ & -0.21 & $<0.01$ \\
\hline \multicolumn{3}{|l|}{$\begin{array}{l}\text { Insulin-mediated glucose disposal } \\
\qquad(\mathrm{mg} / \mathrm{kg} \mathrm{EMBS} \cdot \mathrm{min})^{*}\end{array}$} \\
\hline \multicolumn{3}{|l|}{$\begin{array}{l}\text { Low-dose insulin infusion } \\
\qquad\left(40 \mu \mathrm{U} / \mathrm{m}^{2} \cdot \mathrm{min}\right)\end{array}$} \\
\hline Total (SubmaxM) & 0.19 & $<0.01$ \\
\hline Oxidation & 0.19 & $<0.01$ \\
\hline Storage & 0.06 & NS \\
\hline \multicolumn{3}{|l|}{$\begin{array}{l}\text { High-dose insulin infusion } \\
\qquad\left(400 \mu \mathrm{U} / \mathrm{m}^{2} \cdot \mathrm{min}\right)\end{array}$} \\
\hline Total $(\operatorname{MaxM})$ & 0.34 & $<0.0001$ \\
\hline Oxidation & 0.29 & $<0.0001$ \\
\hline Storage & 0.23 & $<0.01$ \\
\hline
\end{tabular}

Dependent variable $=$ percent weight change $/$ year. ${ }^{*}$ EMBS $=$ fat-free mass $+17.7 \mathrm{~kg}(17)$.
Change in weight and change in insulin sensitivity. $124 \mathrm{sub}$ jects had a euglycemic clamp during their final admission (mean insulin concentrations \pm SD were $1,008 \pm 337$ for Sub$\operatorname{maxM}$ and $16,900 \pm 4,650$ pM for MaxM). The relationship between the change in weight (kilograms) and the changes in insulin action were $r=-0.40(P<0.0001)$ for SubmaxM and $r$ $=-0.52(P<0.0001)$ for MaxM (Fig. 4). When one subject (indicated by asterisk in the figure) was deleted as an outlier, the latter relationship was stronger $(r=-0.57, P<0.0001, n$ $=123$ ). The slope of the relationship (in $\mathrm{mg} / \mathrm{kgEMBS} \cdot \mathrm{min}$ per $\mathrm{kg}$ body wt) between change in weight and change in MaxM was steeper $(\beta=-0.134, n=124)$ than that of the cross-sectional relationship of weight and $\operatorname{MaxM}(\beta=-0.030, n=192)$.

\section{Discussion}

This group of 192 nondiabetic Pima Indians gained a signifcant amount of weight over $3.5 \mathrm{yr}$ of follow-up, but the more insulin-resistant subjects gained the least. Insulin resistance, whether or not it was corrected for the initial body weight, was associated with a lower rate of weight gain than insulin sensitiv-

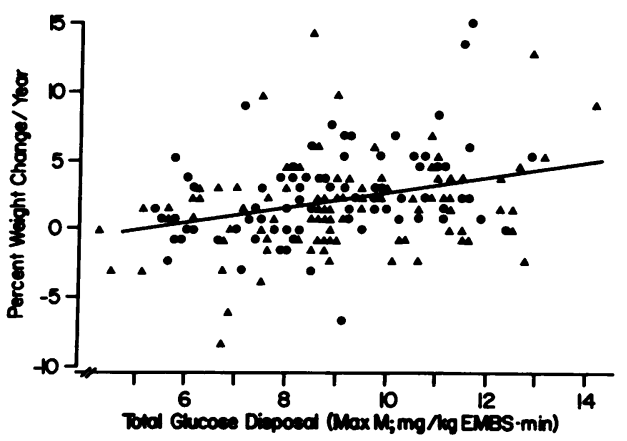

Figure 2. Correlation between glucose disposal at maximum-stimulating insulin concentrations (MaxM) and the percent weight change per year in 104 male ( $\Delta)$ and 88 female (๑) nondiabetic Pima Indians $(r=0.34, P<0.0001, \beta=0.55)$. EMBS = fat-free mass $+17.7 \mathrm{~kg}$ (17). 24 observations hidden. 


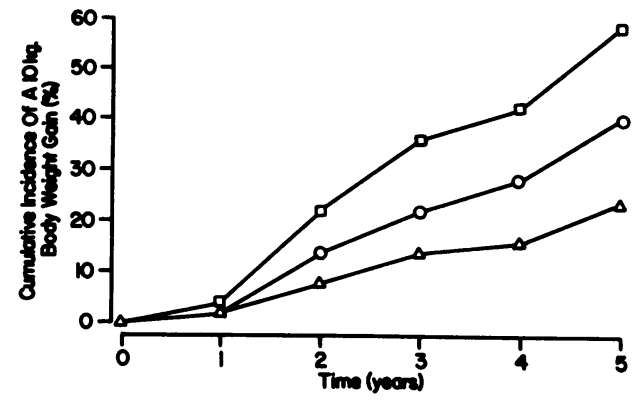

Figure 3. The effect of three different values of glucose disposal at maximum-stimulating insulin concentrations (MaxM) on the cumulative incidence of a 10-kg weight gain calculated from 192 nondiabetic Pima Indians. The upper line ( $(\square)$ represents the 90 th percentile of MaxM (11.5 mg/kgEMBS - min), the middle line (๑) represents the mean $(8.9 \mathrm{mg} / \mathrm{kgEMBS} \cdot \mathrm{min})$, and the lower line $(\Delta)$ represents the 10th percentile $(6.1 \mathrm{mg} / \mathrm{kgEMBS} \cdot \mathrm{min})$. The hazard rate ratio of a 10-kg weight gain is 3.8 (95\% confidence interval 1.7-8.6) comparing the 90th and the 10th percentile of MaxM. EMBS = fat-free mass $+17.7 \mathrm{~kg}(17)$.

ity. This relationship was independent of age, sex, and 24-h energy expenditure.

These findings are contrary to the hypothesis suggesting that insulin resistance, or its consequent hyperinsulinemia, predisposes to obesity. Based on in vivo and in vitro fat cell studies, Arner (6) postulated that the hyperinsulinemia of insulin resistance would suppress insulin-sensitive lipolysis in the adipocyte, thereby leading to further fat accumulation. Felig (7) hypothesized that resistance to the insulin-mediated component of the thermogenic effect of food could lead to weight gain. However, this component is only a small fraction of the total 24-h energy expenditure, and there is even considerable controversy about whether such a defect exists in insulin-resistant individuals (23). The effect of insulin on hunger and food intake has attracted considerable research, largely in animals, over the last 30 years (24). Some investigators have found that insulin stimulates food intake $(8,25)$, whereas others have found insulin suppresses it (26).

The current study examines the effect of insulin resistance on weight change in a longitudinal manner in humans. The Pima Indians are an obese population, and the vast majority of the subjects in this study gained weight. Whether this effect of

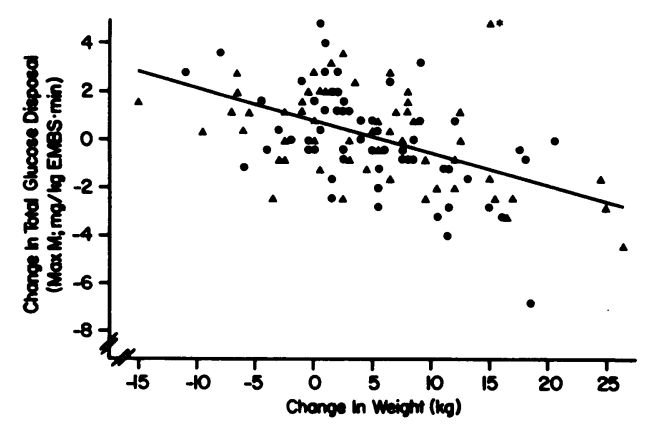

Figure 4. Correlation between the change in glucose disposal at maximum-stimulating insulin concentrations (MaxM) and the change in weight in 59 male $(\Delta)$ and 65 female (๑) nondiabetic Pima Indians $(r=-0.52, P<0.0001, \beta=-0.134 \mathrm{mg} / \mathrm{kgEMBS} \cdot \min$ per $\mathrm{kg})$. Elimination of the outlier $\left(^{*}\right)$ strengthened the correlation $(r=-0.57$, $P<0.0001, \beta=-0.143 \mathrm{mg} / \mathrm{kgEMBS} \cdot \min$ per $\mathrm{kg}) . \mathrm{EMBS}=$ fat-free mass $+17.7 \mathrm{~kg}(17)$. Eight observations hidden. insulin resistance on weight change will be seen in more weight-stable populations is not known.

The reliability of the tracer technique employed in this study to determine hepatic glucose production has been questioned (27). Errors in the estimation of hepatic glucose production during the low-dose infusion will add to the imprecision of SubmaxM as a measurement. MaxM, on the other hand, is measured at a supraphysiological insulin concentration which completely suppresses hepatic glucose production making it a more accurate measurement. This may explain why MaxM was more powerful than SubmaxM at predicting weight change in almost all analyses.

Insulin resistance is the third metabolic predictor of weight change to be described in this population, the other two being resting metabolic rate (28) and respiratory quotient (9). All three parameters show the same patterns in relationship to body weight. Obese people tend to have high absolute resting metabolic rates, low respiratory quotients (i.e., higher ratio of fat:carbohydrate oxidation), and insulin resistance in cross-sectional analysis. On the contrary, in longitudinal analysis, a low relative resting metabolic rate, a high respiratory quotient, and insulin sensitivity are associated with weight gain; in other words the directions of the relationships with body weight are reversed. Furthermore, a change in body weight itself is associated with a change in insulin sensitivity, such that weight gain results, on average, in greater insulin resistance. The slope of the change in insulin sensitivity for the change in body weight $(-0.134 \mathrm{mg} / \mathrm{kgEMBS} \cdot \mathrm{min}$ per $\mathrm{kg})$ is $\sim 4.5$ times steeper than the cross-sectional slope between insulin sensitivity and body weight $(-0.030 \mathrm{mg} / \mathrm{kgEMBS} \cdot \min$ per $\mathrm{kg})$. Therefore, weight gain is associated with increased insulin resistance beyond that which can be explained by the cross-sectional data. Again, this is similar to the patterns seen with the increased resting metabolic rate (28) and decreased respiratory quotient (9) associated with weight gain. This suggests the possibility of a negative feedback relationship whereby an increase in weight causes a somewhat exaggerated increase in insulin resistance which in turn serves to slow down the rate of weight gain.

This proposed interaction helps to explain some of the findings in this study which may appear contradictory. If weight gain causes insulin resistance, how can some individuals who are clearly overweight be quite insulin sensitive? It may be that those overweight individuals experienced some weight loss before their first admission, and this resulted in them being somewhat more insulin sensitive for their weight at the beginning of the study. During the follow-up period, they had a much higher chance of gaining weight than those who perhaps experienced some weight gain (and "exaggerated" insulin resistance) before the first admission.

Also, if the insulin resistance induced by weight gain does attenuate further weight gain, how can the presence of such an obese, yet insulin-resistant population like the Pimas (5) be explained? Although we have shown that insulin sensitivity predicts weight gain, clearly it cannot be the major driving force for the widespread gross obesity in the population because of its apparent negative feedback relationship with weight gain. However, in the presence of some major energy imbalance (such as a hypercaloric diet, decreased physical activity), we would speculate that the degree of insulin resistance or insulin sensitivity may have a modulating effect on body weight, thereby limiting the impact of large changes in energy balance on body weight. This modulating effect may be weaker 
in the more obese subjects who are closer to the lower physiological limits of insulin sensitivity.

By what mechanisms might insulin resistance limit weight gain? Glucose oxidation was a stronger predictor of weight change than was glucose storage or insulinemia. This implies that the mechanisms may involve the control of glucose oxidation, and this is supported by the finding that a low 24-h respiratory quotient (an independent measurement of a low glucose oxidation relative to lipid oxidation) is associated with a slower rate of weight gain (9). Because glucose and lipid oxidation are closely reciprocally related, it may be the control of lipid oxidation which is important and the glucose oxidation rates are simply reciprocal reflections (29). However, this is less likely because glucose oxidation seems to take priority over lipid oxidation, especially during and after meals (30). Mechanisms which lower glucose oxidation would have two important effects on energy balance: $(a)$ the reciprocal increase in fat oxidation needed to meet energy demands would limit fat storage; (b) a higher proportion of a given oral carbohydrate load tending to be directed to storage as glycogen rather than to oxidation, perhaps thereby diminishing the signals for food intake $(31,32)$. In his paper, Flatt proposed that insulin resistance represents a mechanism which tends to limit further increase in adipase tissue mass (31). Although insulin resistance, as we measured it using the euglycemic clamp, manifests as defects in both glucose oxidation and glucose storage, Felber et al. (33) have shown that under more physiological conditions, the defect in glucose oxidation is dominant. The higher glucose and insulin responses to oral glucose seen in insulin-resistant subjects overcomes the deficit in glucose storage, whereas the deficit in glucose oxidation remains.

We conclude that within this weight-gaining population of nondiabetic Pima Indians, insulin resistance is associated with a lower rate of body weight gain and, more specifically, it seems that low glucose oxidation secondary to weight gain may attenuate further weight gain.

\section{Acknowledgments}

We gratefully acknowledge the inspiring comments of Dr. J. P. Flatt; the help of Carol Lamkin, the head nurse of the Clinical Research Unit; the work of Vicky Boyce and the dietary staff; the supply of insulin from Nordisk (Bethesda, MD); the technical, nursing, and secretarial assistance of Thomas Anderson, John Brown, Aileen Coyne, Susan Elson, Revina Frank, Margie Goldsmith, Inge Harper, Christina Hendricks, Donna Judd-Paddilo, Pat Moulsoff, Harlan Osife, Victoria Ossowski, Vera Rodriguez, Donna Rush, Karen Stone, Pam Thulliez, Dorothy Willer, and Debbie Wolfe-Lopez; the assistance of Sonja Antone, Ramona Ruiz, and the other National Institutes of Health staff in the Gila River Indian Community; and the help and cooperation of residents and leaders of the Gila River Indian Community.

\section{References}

1. Kolterman, O. G., R. S. Gray, J. Griffin, P. Burstein, J. Insel, J. A. Scarlett, and J. M. Olefsky. 1981. Receptor and postreceptor defects contribute to the insulin resistance in noninsulin-dependent diabetes mellitus. J. Clin. Invest. 68:957-969.

2. Bogardus, C., S. Lillioja, B. V. Howard, G. Reaven, and D. Mott. 1985. Relationship between insulin secretion, insulin action, and fasting plasma glucose in nondiabetic and noninsulin-dependent diabetic subjects. J. Clin. Invest. 74:1238-1246.

3. Bogardus, C., S. Lillioja, J. Foley, L. Christin, D. Freymond, B. Nyomba, P. H. Bennett, G. Reaven, and L. Salans. 1987. Insulin resistance predicts the development of non-insulin dependent diabetes mellitus in Pima Indians. Dia betes. 36(Suppl. 1):47a. (Abstr.)

4. Knowler, W. C., D. J. Pettitt, P. J. Savage, and P. H. Bennett. 1981. Diabetes incidence in Pima Indians: contributions of obesity and parental diabetes. Am. J. Epidemiol. 113:144-156.
5. Nagulesparan, M., P. J. Savage, W. C. Knowler, G. C. Johnson, and P. H. Bennett. 1982. Increased in vivo insulin resistance in non-diabetic Pima Indians compared with Caucasians. Diabetes. 31:952-956.

6. Arner, P. 1988. Control of lipolysis and its relevance to development of obesity in man. Diabetes Metab. Rev. 4:507-515.

7. Felig, P. 1984. Insulin is the mediator of feeding-related thermogenesis: insulin resistance and/or deficiency results in a thermic defect which contributes to the pathogenesis of obesity. Clin. Physiol. 4:267-273.

8. Jeanrenaud, B. 1988. Neuroendocrine and metabolic basis of type II diabetes as studied in animal models. Diabetes Metab. Rev. 4:603-614.

9. Zurlo, F., S. Lilloja, A. Esposito-Del Puente, B. L. Nyomba, I. Raz, M. F. Saad, B. Swinburn, C. Bogardus, and E. Ravussin. 1990. Low ratio of fat to carbohydrate oxidation as predictor of weight gain: study of 24-h RQ. Am. J. Physiol. 259:E650-E657.

10. Goldman, R. F., and E. R. Buskirk. 1961. A method for underwater weighing and the determination of body density. In Techniques for Measuring Body Composition. J. Brozek and A. Henschel, editors. National Academy of Sciences/National Research Council, Washington, DC. 78-106.

11. Keys, A., and J. Brozek. 1953. Body fat in adult man. Physiol. Rev. 33:245-325.

12. National Diabetes Data Group. 1979. Classification and diagnosis of diabetes and other categories of glucose intolerance. Diabetes. 28:1039-1057.

13. Ravussin, E., S. Lillioja, T. E. Anderson, L. Christin, D. Freymond, and C. Bogardus. 1986. Determinants of 24-hour energy expenditure in man: methods and results using a respiratory chamber. J. Clin. Invest. 78:1568-1578.

14. DeFronzo, R. A., J. D. Tobin, and R. Andres. 1979. Glucose clamp technique: a method for quantifying insulin resistance. Am. J. Physiol. 237:E214-E223.

15. Bogardus, C., S. Lillioja, D. Mott, G. R. Reaven, A. Kashiwagi, and J. E. Foley. 1984. Relationship between obesity and maximal insulin stimulated glucose uptake in vivo and in vitro in Pima Indians. J. Clin. Invest. 73:800-805.

16. Steel, R. 1959. Influences of glucose loading and of injected insulin on hepatic glucose output. Ann. NY Acad. Sci. 82:420-430.

17. Lillioja, S., and C. Bogardus. 1988. Obesity and insulin resistance. Lessons

18. Best, J. D., G. T. Taborsky, Jr., J. B. Halter, and D. Porte, Jr. 1981. Glucose disposal is not proportional to plasma glucose level in man. Diabetes. 30:847-850.

19. Herbert, V., K. Lau, C. W. Gottlieb, and S. J. Bleicher. 1965. Coated charcoal immunoassay of insulin. J. Clin. Endocrinol. Metab. 25:1375-1384.

20. Yalow, R. S., and S. A. Berson. 1960. Immunoassay of endogenous plasma insulin in man. J. Clin. Invest. 39:1157-1167.

21. Harrel, F. E. 1986. The PHGLM procedure. In SAS Institute Inc. SUGI Supplemental Library User's Guide. 5th ed. SAS Institute, Cary, NC. 437-466.

22. Oldham, P. D. 1962. A note on the analysis of repeated measurements of the same subjects. J. Chron. Dis. 15:969-977.

23. D’Alessio, D. A., E. C. Kavle, M. A. Mozzoli, K. J. Smalley, M. Polansky, Z. V. Kendrick, L. R. Owen, M. C. Bushman, G. Boden, and O. E. Owen. 1988 Thermic effect of food in lean and obese men. J. Clin. Invest. 81:1781-1789.

24. Grossman, S. P. 1986. The role of insulin and glucagon in the regulation of food intake and body weight. Neurosci. Biobehav. Rev. 10:295-315.

25. Rodin, J. 1985. Insulin levels, hunger, and food intake: an example of feedback loops in body weight regulation. Health Psychol. 4:1-24.

26. Woods, S. C., D. Porte, Jr., E. Bobbioni, E. Ionescu, J. F. Sauter, F. Rohner-Jeanrenaud, and B. Jeanrenaud. 1985. Insulin: its relationship to the central nervous system and to the control of food intake and body weight. Am. J. Clin. Nutr. 42:1063-1071.

27. Yki-Jarvinen, H., A. Consoli, N. Nurjhan, A. A. Young, and J. F. Gerich. 1989. Mechanism for underestimation of isotopically determined glucose disposal. Diabetes. 38:744-751.

28. Ravussin, E., S. Lillioja, W. C. Knowler, L. Christin, D. Freymond, W. G. H. Abbott, V. Boyce, B. W. Howard, and C. Bogardus. 1988. Reduced rate of energy expenditure as a risk factor for body-weight gain. N. Engl. J. Med. 318:467-472.

29. Randle, P. J., P. B. Garland, C. N. Hales, and E. A. Newsholme. 1963. The glucose fatty-acid cycle: its role in insulin sensitivity and the metabolic disturbances of diabetes mellitus. Lancet. i:785-789.

30. Flatt, J. P., E. Ravussin, K. J. Acheson, and E. Jéquier. 1985. Effects of dietary fat on postprandial substrate oxidation and on carbohydrate and fat balances. J. Clin. Invest. 76:1019-1024.

31. Flatt, J. P. 1988. Importance of nutrient balance in body weight regulation. Diabetes Metab. Rev. 4:571-581.

32. Abbott, W. G. H., B. V. Howard, L. Christin, D. Freymond, S. Lillioja, V. L. Boyce, T. E. Anderson, C. Bogardus, and E. Ravussin. 1988. Short-term energy balance: relationship with protein, carbohydrate, and fat balances. Am. J. Physiol. 255:E332-E337.

33. Felber, J.-P., E. Ferrannini, A. Golay, H. U. Meyer, D. Thiébaud, B. Curchod, E. Maeder, E. Jéquier, and R. A. DeFronzo. 1987. Role of lipid oxidation in pathogenesis of insulin resistance of obesity and type II diabetes. Diabetes. 36:1341-1350. 